\title{
A Very Short-Term Load forecasting using Kalman filter for Load Frequency Control with Economic Load Dispatch
}

\author{
R. Shankar*, K. Chatterjee and T.K. Chatterjee \\ Dpt. of Electrical Engineering, Indian School of Mines, Dhanbad, India - 826004
}

Received 3 July 2011; Accepted 5 August 2012

\begin{abstract}
In this paper we have proposed a control technique for the automatic generation control of multi generating power unit of the interconnected power system. This technique established the relationship between the economic load dispatch and load forecasting mechanism to the classical concepts of the load frequency control (LFC). The LFC system monitors to keep the power system frequency at nominal value, generator output according to the load demand and net interchange scheduled tie line power flows within prescribed limit among the different control area of the power system. Due to relatively fast area load demand fluctuations and accordingly slow response of instantaneous estimate of area control error (ACE), we need some load forecasting technique for better dynamic system response as well as improved \& effective load frequency control to the power system. Load prediction technique has been accomplished using the klaman filter prediction recursive algorithms and a bank of hourly predicted load data is obtained and then the concepts of 5 - minute look ahead forecasting technique is applied and finally total load is shared among the different generating units according to the calculation of economic load dispatch via participation factor's. Results and Discussion section of this paper of simulated interconnected system's graphs support this new technique wisely.
\end{abstract}

Keywords: Economic Load Dispatch, Load Frequency Control (LFC), Short-term load prediction, Kalman filter, Genetic Algorithm (GA) optimization technique

\section{Introduction}

As load frequency control (LFC) is very important issue in the power system, operation and control for sufficient and reliable electric power with good quality in efficient way. The most important planning resources for power system to forecast the future load demand in the present scenario and also one of the essential requirement for the efficient operation and planning of the power system. The main components of the load frequency control is to keep the frequency nearly at constant value $(50 \mathrm{~Hz}$ in India) and to keep the net interchanged tie- line power flow within prescribed limit and secondly to consider the concepts of the economic load dispatch. Further we can get the more accurate load frequency control mechanism, if we incorporate the load prediction technique to automatic generation control (AGC), because load frequency control is most important and power full mechanism to the power system to balance between the net generated power and demanded power via keeping the frequency at prescribed nominal value as well as net interchanged tie-line power within the prescribed limit. So, it more important to have a control mechanism including the concepts of load forecasting as well as economic load dispatch for the load frequency control to the power system for getting the better economic generation, system security, power management and planning, more reliable and uninterrupted power supply system for all generation, transmission and distribution of the power system. In some past decades several classical

*E-mail address: ravi060173@gmail.com

ISSN: 1791-2377 @ 2012 Kavala Institute of Technology. All rights reserved. theory of automatic generation control for interconnected power system has been investigated by different authors $M$. L. Kothari, J. Nanda \& D.P. Kothari [4], O. I. Elgard \& C. Fosla [14], Chidambaram IA \& Valusami S [29] and A. Papalexopoulos [30], R.P. Shulte [20]. So in this paper, we are emphasis the new concepts including the load prediction technology in conjunction with economic load dispatch is consider for the load frequency control of the interconnected power system. There are several literature related to the short term load prediction technique has been reported in some past decades H.M. Al-Hamadi through Kalman filtering algorithm with moving window weather and load model [9], five short term forecasting methods by Ibrahim Mogharam [17], J. P. Rothe, and a comparisons between load forecasting method by K. Liu, et al. [31]. Based upon the literature survey load forecasting method can be classified into two groups.

a) Parametric- based method and

b) Artificial-intelligence based technique.

The first method comprises the load model as mathematical function proposing different methods i.e. Time series by M. T. Hagan [32], general exponential smoothing by W.R. Chrstiaanse [33], Adaptive weather-sensitive model by R. Campo and P. Ruiz [34], Iteratively reweighted leastsquare algorithm model by M. E. El-Hawary \& G. A. Mbamalu [35], multiple correlation models by K.Srinivas \& R. Pronovast [36], application and implementation of least absolute value parameter estimation based on linear programing by s. Soliman \& R. Pronovast [37], reference 
book by R. G. Brown[38] and many more methods are investigated by different authors describing the Auto Regression Model (ARs), Moving-Average Model (MAs), Auto-Regression Moving - Average Model (ARMAs), Auto Regression Integrated Moving - Average (ARIMAs) etc. The second method used the concepts of the Neural Network for load forecasting i.e. comparison of methods [16] and involving Neural network concepts for forecasting by several authors i.e. R.C. Bakirtzis [21], H. S. Hippert [22], C. N. Lu \& C. E. Pedriera [23] .The all techniques mainly use the following concepts for load forecasting through different forecasting algorithms as to find the,
a) Past load data
b) To identify the system model
c) Parameters estimation
d) Load prediction algorithms and
e) Forecasted load.

In this paper, initially the different generating units (thermal, hydro and gas) is simulated or modelled in MATLAB and SIMULATION Toolbox. After successful modelling the concepts of economic load dispatch is taken into account by the means of unit participation factors, which insuring the proper and accordingly demanded load sharing among the different generating units according to their generation and economics. From after the complete simulation work, then the load prediction technology is incorporated to the system via the recursive kalman filter prediction approach, H.M. Al-Hamadi \& Soliman [9], Danial J. Trudnowski, Warren L. McReynold \& Jeffery M. Jonson [15], M. Gasttaldi, R. Lamedica, A. Nardecchia and A. Prudenzi [24] or kalman filter load forecasting technique, this hourly forecasting data is then interpolated up to 5 minute of regular interval and 5-minute ahead to the real time forecasting is successfully obtained, hence the new concepts is developed knows as "very short term load prediction". This new concepts is incorporated to the classical load frequency control mechanism also taking to their economics of generation by the use of the concept of economic load dispatch via participation factors to each electrical generating unit of the power system. The whole process is optimized and corresponding optimal gain of the integral controller (secondary controller) for each control area and different system parameters is obtained using the concepts of the genetic algorithms and its optimization technique. As a whole, this research paper can be categorized into following steps,

A) Study and analysis of the classical load frequency control, economic load dispatch and load prediction technique.

B) Modelling of the multi area interconnected (hydro, thermal and gas) power system.

C) Generation allocation of each generating unit via unit's participation factors.

D) Load forecasting via Kalman filter algorithms.

E) Development of "a very short-term load prediction technique" approach.

F) Optimization for the optimal gain of the secondary controller (integral controller) through Genetic Algorithm Optimization Technique.

\section{Modelling of the Interconnected Power System}

For the power system under consideration in this paper containing two control area in which one of them, first control area containing the combination of generating unit hydro thermal and gas and second control area containing the combination of thermal and hydro generating unit. The detail modelling, control and stability is discussed by O.E. elgerd in " electric Energy System Theory (second edition)" [2], Kundur P. " Power System Stability and control” [10], K. S. S. Ramakrishna and Pawan Sharma [3] and "Dynamic models for steam and hydro turbines in power studies" IEEE committee report [11]. Both control area are connected through tie line for their net interchange tie line power. The detail block diagram of transfer function of the power system under studies is shown below.

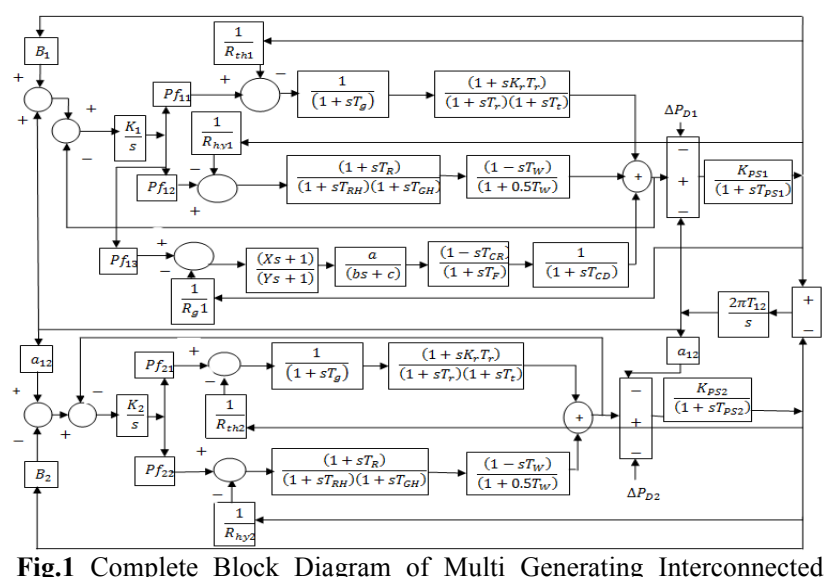
Power System.

\section{Generation Allocation of the Generating Units}

Since we know that each control area contains different driving source of the generating units (hydro, thermal, gas, nuclear, wind etc.). These generating units ensuring the fulfilment of the demanded electrical load in the view of almost constant standard frequency $(50 \mathrm{~Hz}$ in India) and net interchanged tie-line power flow between the different control area of the power system via the concepts the load frequency control mechanism. To fulfil of the task of different control area, must be agree with the coordination of the calculation of economic load dispatch (discussed by A.J. Wood and Woolenberg. B. F. "Power Generation Operation \& control", John Wiley and sons, 1998 [1]) and the automatic generation control concepts of the power system. Thus, this coordinated logic gives the better and rich information relating that, how much each generating unit will participate to the total load sharing out of the total demanded electrical load in context with their economics and generation, this lead to introduce the concepts of the unit's participation factors. Participation factor defined as the rate of change of each unit's output with respect to a change in total generation of that control area. From the definition and properties of the participation factor its summation is equal to unity for each respective control area. When the economic load dispatch calculation is performed then the sum of the present unit generation equal to the total generation then it will assigned as the base point generation. This base point generation will be the most economic output of the every generating units of the power system. Thus we will assigned the generation allocation of the multiple 
generating unit with respect to total change in generation output with the help of the conjunction with the load frequency control mechanism and the concepts of economic load dispatch.

$P_{\text {ides }}=P_{\text {ibase }}+p f_{i} \times \Delta P_{\text {total }}$

$P_{\text {ides }}=$ Desired output from unit I, $\Delta P_{\text {total }}=$ Change in total generation, $P_{\text {ibase }}=$ Base-point generation for $\mathrm{i}^{\text {th }}$ unit, $p f_{i}=$ Participation factors for $\mathrm{i}^{\text {th }}$ unit

$\sum p f_{i}=1$

To find out the participation factors of each unit, we use the concepts of economic load dispatch calculation and the following equations accomplish the execution of the given task. The quadratic cost function of the power system is given as

$F_{i}\left(P_{G i}\right)=\alpha_{i}+\beta_{i} P_{G i}+\gamma_{i} P_{G i}^{2}$

$\alpha_{i}, \beta_{i}$ and $\gamma_{i}$ are the coefficient of the cost function and $P_{G i}$ is power generation of the $i^{\text {th }}$ unit.

$\min . F(T)=\sum F_{i}\left(P_{G i}\right)$

Power balance constraint is given as

$\sum P_{G i}=P_{D}+P_{L}$

Where,

$P_{D}=$ load demand and $P_{L}=$ transmission losses and inequality is given as

$P_{G i}^{\min } \leq P_{G i} \leq P_{G i}^{\max }$

$P_{G i}^{\min }, P_{G i}^{\max }$ are their minimum and maximum power generation of the $i^{\text {th }}$ unit.

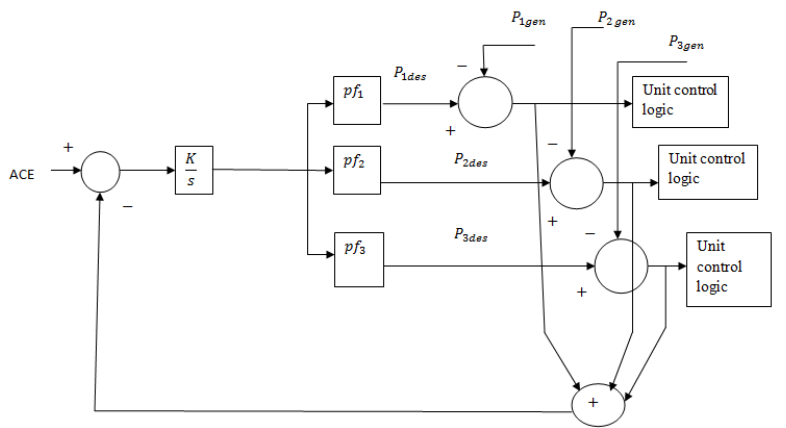

Fig.2 Complete Block Diagram of Generation Allocation of Multi Generating Units.

\section{Short term load forecasting using kalman filter algorithm}

The complete derivation and application of the Kalman filter and its brief theory is explained in some literature which has been discussed in introduction section and relating reference book by R. G. Brown [38], the only necessary equation for the development of the basic equation for the kalman filter which is used as predictor and correction is given below, the information used at time $x(k-1)$ to obtained the estimation at time of $(k)$ and in discrete-time format the signal model is represented in state-space form is given as.
$x(k+1)=A(k) \cdot x(k)+w(k)$

$z(k)=c(k) \cdot x(k)+v(k)$

Since kalman filter prediction is mainly based on recursive equation iterated successively to find out the optimal estimation of the given equation. The kalman gain is obtained through the standard equation as,

$$
\begin{aligned}
& K(k)=A(k) P\left(\frac{k}{k-1}\right) C^{T}(k) \cdot\left(C(k) P\left(\frac{k}{k-1}\right) C^{T}(k)+\right. \\
& R(k)+)^{-1}
\end{aligned}
$$

The new state estimate of the system is given by,

$\widehat{x}\left(\frac{k+1}{k}\right)=A(k) \widehat{x}\left(\frac{k}{k-1}\right)+K(k)\left(y(k)-c(k) \widehat{x}\left(\frac{k}{k-1}\right)\right)$ (10)

Error covariance update is estimated as,

$P\left(\frac{K+1}{K}\right)=$

$A(k) P\left(\frac{K}{K-1}\right) A^{T}(k)-K(k) C(k) P\left(\frac{k}{k-1}\right) A^{T}(k)+Q_{2}(k)$

Where,

$x(k)=n \times 1$ System states system states, $A(k)=n \times n$ Time varying state transition matrix, $z(k)=m \times$ 1 Measurement vector, $c(k)=m \times n$ Time varying output matrix, $W(k)=n \times 1$ Uncorrelated white noise, $V(k)=$ $m \times 1$ Uncorrelated white noise and having zero mean, Q1 and $\mathrm{Q} 2$ = positive semi definite and positive definite matrix respectively.

Zero means, equation hold the relation,

$E[w(k)]=E[V(k)]=0$

And also no time correlation and having known covariance matrix i.e.

$E\left(W(i) W^{T}(j)\right)=E\left[V(i) V^{T}(j)\right]=0$ for $i=j$

And, also known covariance matrices (noise levels) is given as,

$E\left(W(k) W^{T}(k)\right)=Q 1$

$E\left(V(k) V^{T}(k)\right)=Q 2$

Here to enhancement of convergence characteristics of the kalman filter then must be smart choice of the priori estimated state $x_{0}$ and its covariance error $P_{0}$. Equation (7) and (8) may be contained the following assumptions:

a) State transition matrix $\mathrm{A}(\mathrm{k})$ is a constant identity matrix.

b) The error covariance matrix Q1 and Q2 are constant matrix and its value is depends upon the actual characteristics of the past information available of process error and measurement noise respectively. They must be chosen as identity matrix. 
c) Vector $\mathrm{x}(\mathrm{k})$ consist of $\mathrm{N}$-parameter.

d) $\mathrm{C}(\mathrm{k})$ is $\mathrm{N}$-variable time varying row vector which relates the relationship of the load data.

e) $\mathrm{Z}(\mathrm{k})$ represents the optimal estimated load at the instant of time $\mathrm{k}$.

Steps should be followed for prediction algorithm based on kalman filter is,

a) The load data is selected as the input to be predicted via kalman filter algorithm approach, the initial condition of the parameter vector is fixed arbitrarily.

b) Covariance matrix Q1 and Q2 of the equation (14) and (15) are set to unity matrix with appropriate dimension.

c) We go through recursive kalman approach for the first hour of the day and use this result coefficient to be used later for prediction.

d) By using the estimated parameter of the various hours as initial condition for estimating the next hour coefficient by kalman filter.

e) Repeat the above steps for all 24 hours of the day.

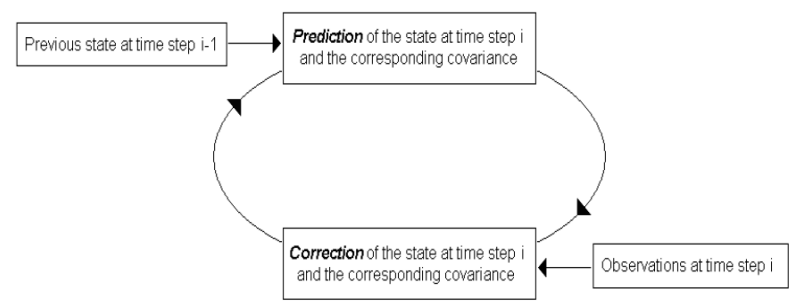

Fig.3 Complete Block Diagram of Kalman Filter Recursive Equation For Prediction Theory.

\section{Five minute ahead load forecasting technique}

It is very important to get the good and improved performance of kalman filter, then it must have some lookahead load and parameter estimation control algorithm to accomplishment of the task we use the forecasted 24 hour load data from kalman filtering approach and we interpolate it at the instant of five minute of interval. Thus we have the bank of five minute forecasted load its load error will fed directly to the given model of the power system as the load changes. Now let us consider $(y(t))$ be the forecasted load at the instant of time t then $y(t+5)$ is forecasted load then the load change will be $y_{d}(t)=y(t+5)-y(t)$; this load changes will be consider at the instant of the time $t$ and interpolate to the circuit system and corresponding five minute look-ahead control algorithm is designed. This five minute load is divided to all generated unit according to their unit participation factors and hence termed as "A very shortterm load prediction technique".

\section{Optimization Technique through Genetic Algorithm}

Genetic algorithm is used to optimize the objective function of the given system which is mainly based on the search technique through natural selection and genetics of the system. Genetic algorithm and its application has been discussed in brief as a tutorial and realization by A. Konark et al (2006) in [6]. For interconnected power system, using the concepts of the genetic algorithm for optimization technique and its related application has been deduced by many authors titled as optimization of interconnected power system through Genetic algorithm by Y.L. Abdel Magid \& M. M. Dawoud [28] and [13], genetic algorithm based optimization of AGC Gains of interconnected power system by Ibraham, Omveer singh and namuail Hassan [7] has been discussed earlier. Since this technique generally converge to global optima over conventional technique because it search the best point from the randomly generated population of point. Its operation is probabilistic transition in nature and their different tools and operators are as follows.

\subsection{Objective function}

The objective function is to minimization the performance index which is the linear combination of the two area deviation of frequency multiplied by their respective bias constant and net tie-line power flow \& of course, these variation are weighted together by a single variable know a ACE (area control error) of the respective power units i.e. differ for hydro \&thermal units. So fitness function to be minimized in this research paper is

$J=\int_{0}^{t}\left(\Delta f_{1}^{2}+\Delta f_{2}^{2}+\Delta P_{t i e 12}^{2}\right) d t$

\subsection{Reproduction}

Selection is the process of selecting the population from the current population which will survive for the next generation population for next process of the Genetic Algorithms. In this paper we select the Roullete Wheel selection process for the selection or reproduction of the next generation population. The brief study has been performed in past some decade.

\subsection{Crossover}

Crossover is also known as recombination of the population or reshuffled the selected population. Here, we select two random selected populations \& then we choose random site $\&$ interchanged the individual Chromosomes with each other and finally produced the new off spring, and we proceed for next process. The performed analysis is discussed by Y.L. Abdel Magid \& M. M. Dawoud [13].

\subsection{Mutation}

In this process, we select the individual bit randomly and interchanged with ' 0 ' or ' 1 ' and it gives some variations in information of the population, although its probability rate is quite small as compare to crossover probability rate.

\subsection{Structure of Genetic Algorithms}

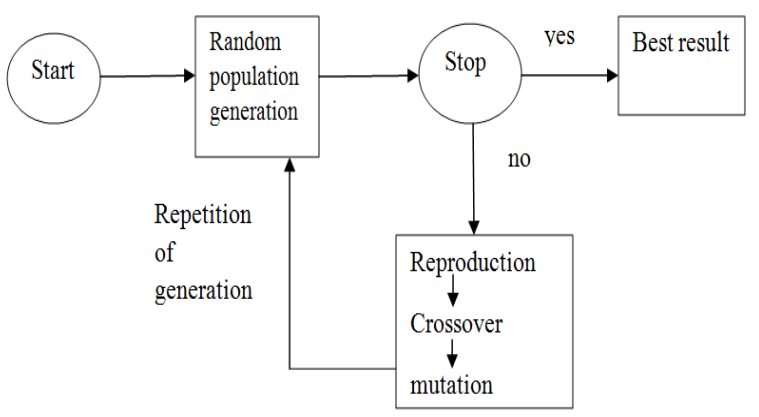

Fig. 4 Complete Block Diagram of the Genetic Algorithm 


\section{Results and discussion}

The proposed design of the integral controller in conjunction with the economic load dispatch i.e. unit's participation factors and load prediction technology has been applied for typically multi generating units of the interconnected power system. The proposed controller is simulated in MATLAB \& SIMULATION TOOLBOX. Kalman recursive theory based, a very short term load prediction technology is implemented. From kalman based forecasted load is obtained then interpolated up to 5 minutes of regular interval and a new concept is developed to 5 minute ahead load forecast methodology, ahead of the real present runing time. This five minute look ahead forecasted load is fed to the area one of the power system and corresponding frequency deviation graph of control area one and control area two of interconnected power system is obtained, which is shown in figure (6) and figure (7). The figure (5) shows the comparison between real time load data graph and forecasted load data which justified the forecasting technique to the real time ahead prediction technology. After feeding the forecasted data to the system, then each generating units will participate according to their participation factors in the contrast of the economic load dispatch calculation. Control input to the integral controller or Area Control Error (ACE) profile deviations with time(minutes) is shown in figure (8) and figure (9) of the control area one and control area two of the given interconnected power system respectively. Hence, the proposed control technique, in conjunction with the load prediction technology (via Kalman recursive prediction theory) and economic load dispatch to the automatic load frequency control mechanism of the power system gives better dynamic response and stable frequency response against the fast fluctuating electrical load of the given interconnected multi generating unit power system.

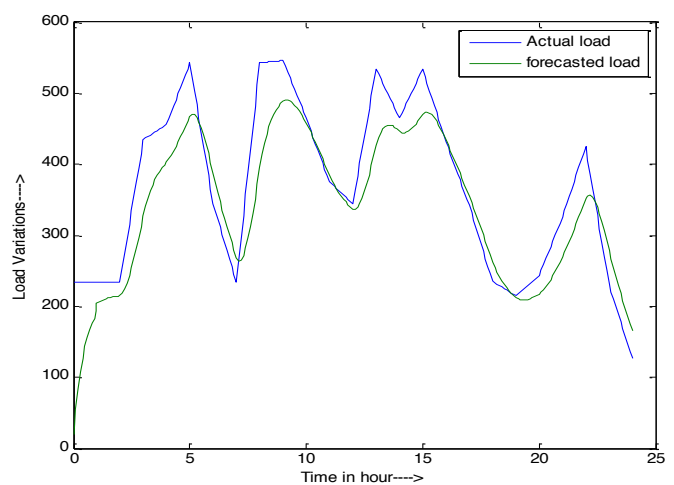

Fig. 5 Comparison between Actual load vs. Predicted load.

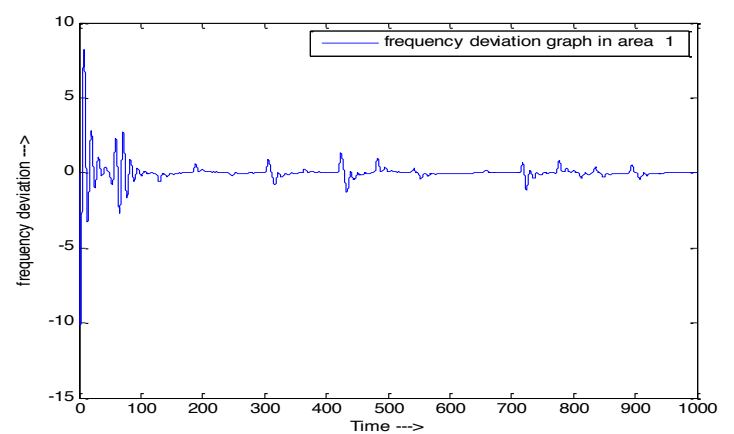

Fig. 6 Frequency deviation graph in area one with time (in minutes)

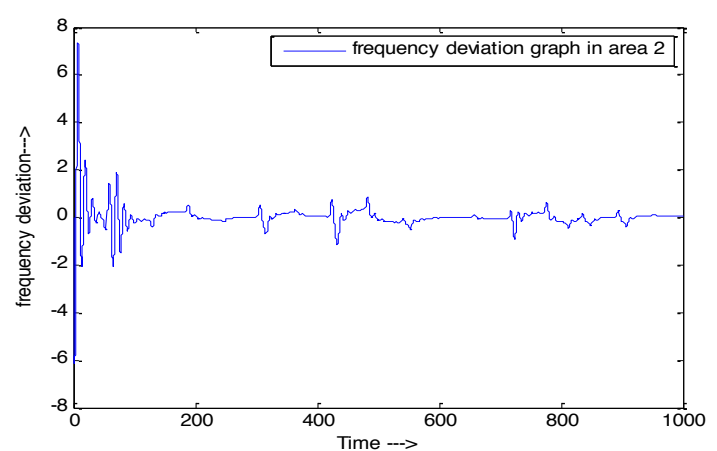

Fig. 7. Frequency deviation graph in area two with time (in minutes)

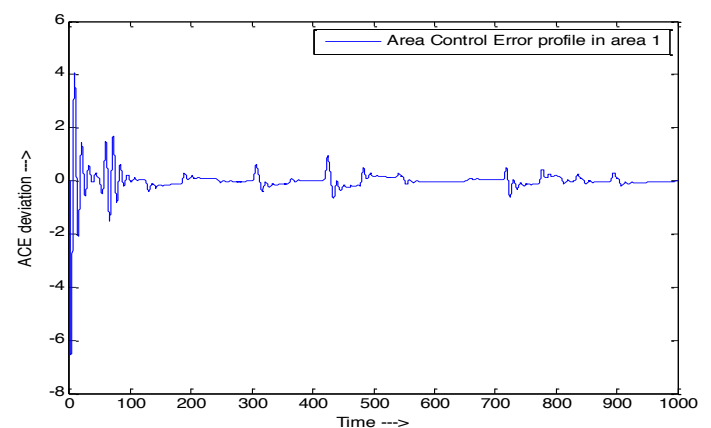

Fig. 8 Area Control Error (ACE) graph with time (in minutes) in area 1

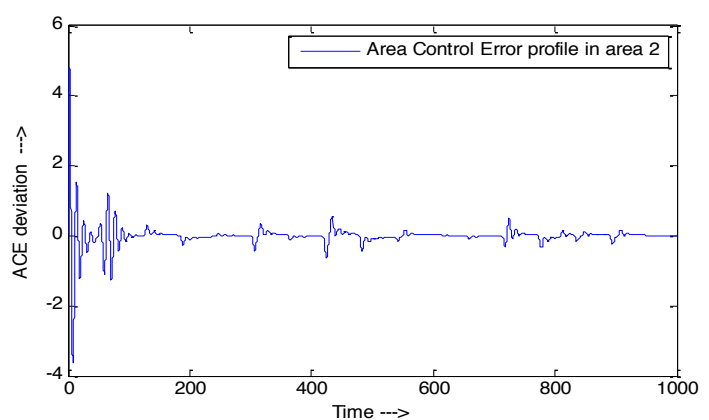

Fig. 9 Area Control Error (ACE) graph with time (in minutes) in area 2.

\section{Conclusion}

In this paper we have proposed a control mechanism, coordinating the concepts of load forecasting technique and economic load dispatch to the classical theory of the load frequency control of the automatic generation control of the power system. The different simulation graphs of frequency deviations, ACE profile deviation graph of both area of the given interconnected power system, comparison graph between forecasted load and actual load shows that the implemented control technique is quite effective, gives better and improved system transient response which helps in stabilising the frequency deviation against the fast fluctuating electrical load at almost constant nominal standard value $(50 \mathrm{~Hz}$ in India) between the different control area as well as most economic generation allocation among the different generating unit of the interconnected power system.

\section{Appendix and Nomenclature:}

Thermal power unit:

$K_{r}($ Coefficient of re-heat steam turbine $)=0.3, T_{r}$ (re-heat time constant $)=10 \mathrm{sec}$. 
$T_{t}($ Turbine time constant $)=0.3 \mathrm{sec}, R_{t h i}$ (speed governor regulation $)=2.4 \mathrm{~Hz} / \mathrm{pu} \mathrm{MW}$

$T_{g}($ Speed governor time constant $)=0.08 \mathrm{sec} ., T_{W}($ wate time constant $)=1.0 \mathrm{sec}$

$R_{\text {hyi }}($ Speed governor regulation $)=2.4 \mathrm{~Hz} / \mathrm{pu} \mathrm{MW}$

Gas power unit:

$X($ Speed governor lead time constant $)=0.6 \mathrm{sec}, Y(($ speed governor lag time constant $)=1.0 \mathrm{sec}$., Valve positional constant $a=1, b=0.05$ and $c=1, T_{F}($ Fuel time constant $)=$ $0.23 \mathrm{sec}$.

$T_{C R}($ Combustion reaction time delay $)=0.3$ sec., $T_{C D}($ Compressor discharge volume time constant $)=0.2 \mathrm{sec}$, $R_{g}($ Speed governor regulation $)=2.4 \mathrm{~Hz} / \mathrm{pu} \mathrm{MW}$
Hydro power unit:

$T_{R}($ Speed governor rest time $)=5.0 \mathrm{sec} ., T_{R H}($ Transient

droop time constant $)=28.75$

$T_{G H}$ (Main servo time constant $)=0.2 \mathrm{sec}$.

Power system:

(Gain of the power system) $K_{P 1}=K_{P 2}=120 \mathrm{~Hz} / \mathrm{pu}$,

(Time constant of the power system) $T_{P 1}=T_{P 2}=20 \mathrm{sec}$.

\section{Acknowledgement:}

The authors sincerely acknowledge the financial support provided by the ISM, Dhanbad for carrying out the present work.

\section{References}

1. A.J.Wood and Woolenberg .B.F. " Power Generation Operation \&Control",John Wiley\&sons, 1998.

2. O.E. Elgerd, “ Electric Energy Systems Theory(second Edition)",Newwork :McGrawHill, Inc.1982,pp 315-389.

3. K. S. S. Ramakrishna, Pawan Sharma, T. S. Bhatti, Automatic generation control of interconnected power system with diverse sources of power generation, International Journal of Engineering, Science and Technology, vol.2, no.5, 2010,pp.51-65

4. M.L.Kothari, J.Nanda, D.P.Kothari and D.Das. "Discrete-mode Automatic generation control of a two-area reheat thermal system with new area control error", IEEE Transactions on power systems,Vol.4, No.2,May 1989,pp.1988-1994.

5. S.C.Tripathy, G.S.Hope and O.P.Malik. "Optimization of loadfrequency control parameters for power systems with reheat steam turbines and governor dead band nonlinearity", IEE Proceedings, Vol. 129,Pt.C,No.1, Jan 1982,pp.10-16.

6. A. Konark et al,(2006) - "multi-objective optimization using GA algorithms"-A tutorial/Reliasation engineering and system safety,91,992-1007

7. Ibraham, Omveer Singh, Namuail Hassan, Genetic Algorithms based scheme for optimization of AGC gains of interconnected power system,Journal of theoretic \& applied information technology, 2005-2009.

8. T.P.ImthiasAhamad,P.S. NagendraRao and P.S.Sastry. "A reinforcement learning approach to automatic generation control", Electric power systems research 2002(63), pp.9-26.

9. H.M. Al-Hamadi, S.A.Soliman, " Short-term electric load forecating based on Kalman filtering algorithm with moving window weather and load model", Electric power system research 68(2004) 47-59.

10. Kundur. P, "Power System Stability and Control", McGraw Hill, New York, 1994

11. "Dynamic Models for steam and Hydro Turbines in Power system studies",IEEE committee report. Transactions in Power Apparatus \& Systems Vol.92,No.6,Nov./Dec.1973,pp.1904-915.

12. Roland R.Yager and Dimitar P.Filev,"Essentials of Fuzzy Modelling and Control",John Wiley \& Sons,Inc.1994H S. Farook, P. SangamasmeswaraRaju optimization of feedback controller power system using Evolutionary Genetic Algorithm, International Journal of Engg. Science \& Tech; vol.3, No.5 May 2011

13. Y.L. Abdel Magid, M. M. Dawoud, Genetic Algorithms Applications in Load Frequency Control,Genetic Algorithms in Engineering Systems: Innovations and Applications, 12-14 September 1995, Conference Publication

14. O. I. Elgerd and C. Fosha, optimum megawatt frequency control of multi-area electric energy systems, IEEE Transactions on Power Apparatus and Systems, vol. PAS-89, no. 4, pp. 556-563, Apr. 1970.

15. Danial J. Trudnowski, Warren L. McReynold, and Jeffery M. Jonson, Real-Time Very Short-Term Load Prediction For PowerSystem Automatic Generation Control, IEEE Trans. On Control Systems Technology, Vol. 9, No. 2, March 2001.

16. K. Lui, S. Subbarayan, R.R. Shoults, M.T. Manery, C. Kwan, F.L. Lewis, J. Naccarion, Comparison of Very Short-Term Load Forecasting Techniques, IEEE Trans. on Power System, Vol. 11, No. 2, May 1996.
17. Ibrahim Moghram, SaifurRahman, Analysis and Evaluation of Five ShortTerm Load Forecasting Techniques, IEEE Trans. on Power System, VOl. 4, No. 4, Oct. 1989.

18. J. P. Rothe, Dr. A. K. Wadhwani,. S. Wadhwani, Short Term Load Forecating Using Multi Parameter Regression, International Journal of Computer Science and Information Security, Vol. 6, No. 2, 2009.

19. H.Danishi, Member, IEEE, and A. Daneshi, Real Time Load Forecasting in Power System, DPRT 2008, 6-9 April 2008, Nanjing China.

20. R.P. Shulte, An Automatic Generation Control Modification For Present Demands on Interconnected Power Systems, IEEE Trans. on Power System, Vol. 11, pp. 1286-1294, 1996.

21. R.C. Bakirtzis, V. Petridis, S.J. Klartiz and M.C. Alexladls, A Neural Network Short Term Load Forecasting Model for Greek Power System, IEEE Trans. Power Syst., Vol 11, pp. 858-863, May 1996.

22. H. S. Hippert, C.E. Pedriera, and R.C. Souza, Neural Networks for Short-Term Load Forecasting: A Review and Evaluation, IEEE Trans. on Power System, Vol. 16, No. 1, pp. 44-55, 2001.

23. C. N. Lu, and S Vemuri, Neural Network For Short-Term Load Forecasting, IEEE Trans. on Power System, Vol. 8, No. 8, pp. 336-342, 1993.

24. M. Gastaldi, r. Lamedica, A. Nardecchia, A. Prudenzi, " Short-term forecasting of municipal load through a Kalman Filtering Based Approach", IEEE, 2004.

25. A.Papalexopoulos, T.Hesterburg,A regression-based approach to short term load forecasting, IEEE Trans. Power Syst. 5(4) (1990) 1535-1547.

26. Khaled M. EL-Naggar, and Khaled A. AL-Rumaih, Electric Load Forecasting Using Genetic Based Algorithm, Optimal Filter Estimator and Least Error Squares technique: Comparative Study, World Academy of Science, engineering and Technology 6, 2005

27. A. Asar and J. R. Mcdonald, A Specification of Neural Network Application in the Load Forecasting Problem, IEEE Trans. on Control System technology, Vol. 2, No. 2, 1994, pp. 135-141.

28. Y. L. Abdel Magid, M. M. Dawoud, Tunning of AGC of interconnected reheat thermal systems with genetic algorithms, IEEE-1995.

29. Chidambaram IA, Velusami S, Design of decentralized biased controllers forload-frequency control of interconnected power systems, International Journalof Electric Power Components and Systems, 2005:33(12):1313-1331.

30. A. Papalexopoulos, T. Hesterburg, "A regression-based approach to short-term load forecasting, IEEE Trans. Power system 4 (1990) 1535-1535.

31. K. Liu, et al., "comparison os short-term load forecasting techniques", in: Presented at IEEE PES'95 SM, Portland, 95 SM 547-0 PWRS, 1995.

32. M.T. Hagan, S.M. Behr, “ The time series approach to short-term forecasting”, IEEE Trans. Power Syst. 2(3) (1987) 785-791.

33. W.R. Chrstiaanse, Short-term load forecasting using general exponemtial smoothing, IEEE Trans. Power Apparatus Syst. PAS90 (2) (0971) 900-910.

34. R.Campo, P.Ruiz, Adaptive weather-senitive short-term load forecasting, IEEE Trans. Power Syst, 2 (3) (1987) 592-600. 
35. M.E.El-Hawary, G.A. Mbamalu, short-term power system load forecasting using the iteratively reweighted least-squares algorithm, Electric Power Syst. Res. 19 (1990) 11-22.

36. K.Srinivasan. R.Pronovast, "Short term load forecasting using multiple correlation models, IEEE Trans. Power Apparatus Syst. PAS-94 (5) (1997) 1854-1858.

37. S.Soliman, S. Persaud, K. El-Nagar, M. El-Hawary, Application of least absolute value parameter estimation based on linear programing to short-term load forecasting, Electric Power Energy. 19 (3) (1997) 209-216.

38. R.G. Brown, Introduction to Random Signal Analysis and Kalman Filtering, Wiley, New York,1983. 